\title{
H-BIM AND THE DOMAINS OF DATA INVESTIGATIONS OF HERITAGE BUILDINGS CURRENT STATE OF THE ART
}

\author{
A. Khalil ${ }^{1}$, S. Stravoravdis ${ }^{2}$ \\ ${ }^{1}$ School of Design, Faculty of Liberal Arts \& Sciences, University of Greenwich, London, UK - A.Khalil@greenwich.ac.uk \\ ${ }^{2}$ School of Architecture, University of Liverpool, London, UK - S.Stravoravdis@liverpool.ac.uk
}

KEY WORDS: H-BIM, Heritage Buildings, Documentation, Domains of Data, Investigation, Geometry, Pathology, Performance.

\begin{abstract}
:
Heritage BIM can represent many advantages for heritage building documentation, restoration, retrofitting and management. However, the most complicated challenge concerning H BIM is the inevitability of starting at an intermediate point in the asset's life cycle, which can be much more complex than the relatively straightforward cradle-to-grave model that describes new-build construction (Historic England, 2017). This leads to irregular geometry, non-homogeneous materials, variable morphology, not documented changes, damage and various stages of construction. These challenges put more weight on the surveying, documentation, modelling and visualisation phase within the process of HBIM.

Many investigation tools can be used and combined to document and investigate the fabric of historic buildings. This paper reviews the literature and the state of art of the different domains of data that could be included in the documentation and investigation process of the built heritage, in order to assess the breadth and depth by which heritage buildings can be documented. These data can vary from outer geometry survey, to sub-surface materials and structural integrity investigations, to data concerning the building performance, as well as the historic records concerning the building`s morphology over time, which can help to create a more indepth knowledge about the heritage buildings` status and performance and can create a solid base for any required restoration and retrofitting processes.
\end{abstract}

\section{INTRODUCTION}

Heritage Building Information Modelling (HBIM) is defined by Historic England, (2017) as "a multi-disciplinary process that requires the input and collaboration of professionals with very different skillsets. It is also a fast-developing field in terms of research, official guidance, standards and professional practice". HBIM combines multi-dimensional visualization with comprehensive, parametric databases. It allows to integrate management of graphical and informational data flows. to facilitate collaborative developing the strategy of building project design, construction and facility management among project partners (Fai et al., 2011). It helps to transform individual executors into teams and decentralise tools into complex solutions, this leads to individual tasks being implemented as complex processes; perform life cycle operations of a construction project more effective, faster and with lower cost (Logothetis, Delinasiou and Stylianidis, 2015).

HBIM can represent many advantages to historic buildings. The main advantages of modelling historical buildings are in the integrity of design and visualisation, cost estimation, conflict detection, full planning implementation and improved stakeholder collaboration (Volk, Stengel and Schultmann, 2014). It can also help in automatic measurement, identification and modelling of damaged or non-existent architectural elements (Koller, Frischer and Humphreys, 2009), so, it can be a representation of the historic building's changes over time. Moreover, one of the major benefits of H-BIM is the transmissibility of the information during the life cycle of the heritage building (Banfi et al., 2017). HBIM also can represent a contribution towards energy analysis and economic analysis up to multi-thematic analysis within sustainability (Azhar et al., 2011) (Azhar and Brown, 2009) (Habibi, 2017).

In the heritage buildings' sector many challenges are facing the implementation of Building Information Modelling (BIM) tools, such as the inevitability of starting at an intermediate point in the asset's life cycle, which can be much more complex than the relatively straightforward cradle-to-grave model that describes new-build construction (Historic England, 2017). More challenges are present in the processing of historic buildings: irregular geometry, non-homogeneous materials, variable morphology, not documented changes, damage and various stages of construction (Barazzetti and Banfi, 2017). These challenges put more weight on the surveying, documentation, modelling and visualisation phase in the process of Heritage-BIM.

\section{H-BIM AND THE DOCUMENTATION OF HERITAGE BUILDINGS}

Heritage documentation is seen as the systematic collection and archiving of tangible and intangible elements of historic structures and environments. Its purpose is to supply accurate information that will enable correct conservation, monitoring and maintenance for the survival of the building (Dore and Murphy, 2017) (Letellier, 2007) (Bryan et al., 2009).

HBIM offers very versatile solutions for modelling and managing information relating to existing and heritage buildings. It can be used as a documentation and management tool for conservation work, retrofitting, renovations and building analysis. It can also be used as a research tool for

\footnotetext{
* Corresponding author
} 
documentation and interpretation of historic buildings and representation of changes to the building over time. HBIM can incorporate both quantitative assets (intelligent objects, performance data) and qualitative assets (historic photographs, oral histories, music) (Fai et al., 2011). HBIM data can also include historic texts, archaeological figures, architectural information, administrative data and past drawings, sketches, photos etc. Survey and the acquisition of all possible data is the first step to contribute towards fundamental modelling for building recording and documentation (Cheng, Yang and Yen, 2015).

While the main challenge is the high modelling/conversion effort required for creating semantic BIMs from unstructured survey data and achieving accurate representation of complex irregular objects in heritage buildings and the lack of standards for the representation of objects and information in heritage buildings (Dore and Murphy, 2017).

A wide range of data can be of benefit for the process of documentation, modelling and visualisation of heritage buildings, these data (whether tangible; such as the geometry, materials and structural systems, or intangible; such as the historical record of the building, its cultural assets and its performance) can vary in scope, purpose and investigation tools. These different data can be categorised into four main categories, each domain requiring its own documentation and investigation tools (Figure 1):

- Archaeological and historical data; including the archaeological investigations, historical records and the morphology of the building over time.

- Geometry; including the survey and visualisation of the heritage building in its current state to identify position, size, shape and identity of the components of the outer skin of the historic building.

- Pathology; including the potential damage or decay of the fabric of the historic building, and the investigation of the sub-surface characteristics of its materials and structural systems.

- Performance; including data about the current status of the building`s operability and performance in its various aspects.

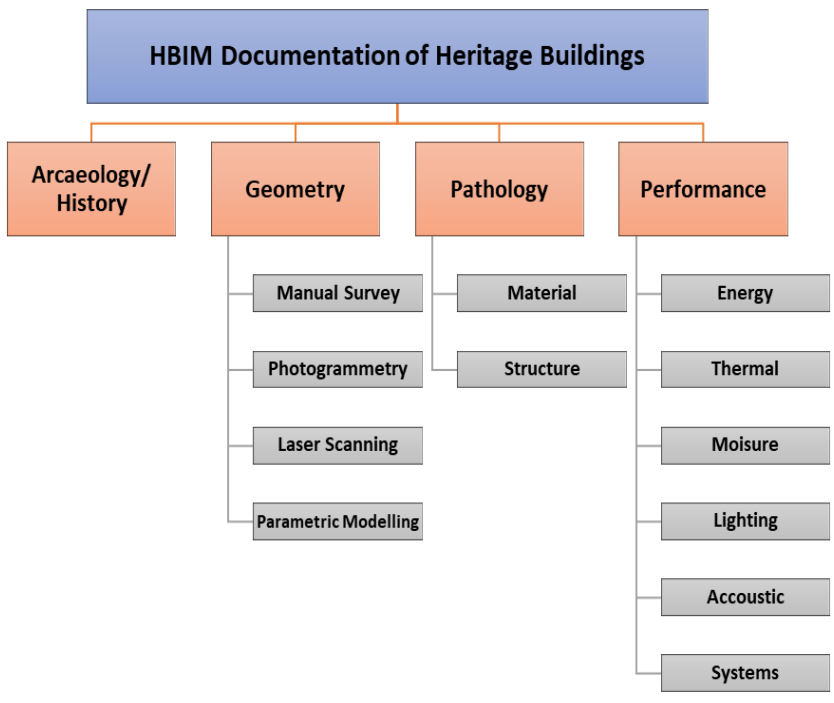

Figure 1 Categorisation of the different domains of data in the documentation of Heritage buildings

\section{ARCHAEOLOGY/ HISTORY}

HBIM offers a process of digitally documenting all the features that are made or incorporated into the heritage building over its life-span, thus affords unique opportunities for information preservation (Albourae, Armenakis and Kyan, 2017). HBIM can combine the tangible geometry of the building with many of its intangible aspects such as historic architectural drawings, historic texts, archaeological figures, architectural information, sketches, photos etc. These data sources can create a better understanding about the building in its current status as well as its historic morphology over time. They can also contribute towards understanding the construction systems of the building and its development through the building's history, as well as building an idea about the materials and technologies used in its construction. This can be also used to disseminate the building and its historic development for the wider audience through modelling the different phases of the building's history. In this sense, more advanced visualization and presentation can be achieved using augmented and virtual reality techniques (AR and VR) (Osello, Lucibello and Morgagni, 2018).

In some cases, when the historic data are scarce, a reverse process starting with the geometric survey and the development of $3 \mathrm{D}$ models of the heritage building can be useful for the interpretation of the monument itself and its historical construction and development over time. An example of this procedure can be seen in the modelling of St. Maria church in Scaria d'Intelvi in Italy, conducted by Brumana et al., (2013). As they started with an accurate 3D survey of the entire church, that allowed the analysis and detailed interpretation of the geometry and the morphology of the structural elements, such as building a hypothesis concerning the building techniques and construction periods of the vaults covering the church. These analyses helped to achieve a stratigraphic study that considers the changes undergone to the church through the centuries (Figure 2) (Brumana et al., 2013).
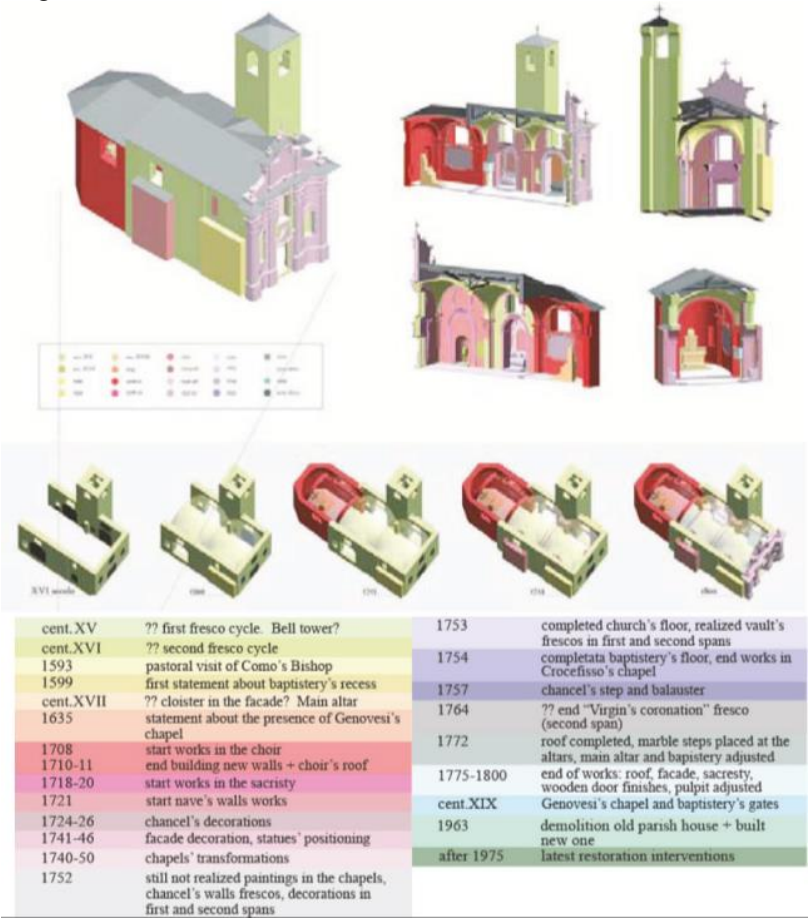

Figure 2: HBIM of the different constructive phases of St. Maria church and its historical transformation. (Brumana et al., 2013) 


\section{GEOMETRY}

Knowledge of the position, size, shape and identity of the components of a historic building or site is a fundamental part of a project related to the conservation of cultural heritage (Historic England, 2018). Geometry capturing of heritage buildings into HBIM platforms is the area that has witnessed a lot of research and development. However, it is still a very challenging process due to the irregular geometry, nonhomogeneous materials, variable morphology, not documented changes, damage and various stages of construction that typically characterises heritage buildings.

HBIM documentation and representation of heritage buildings can be carried out using different techniques with a wide range of accuracy, cost efficiency, time consumption and technologies. A range of techniques can be used from traditional surveying techniques to photogrammetry to laser scanning.

\subsection{Traditional Survey}

Hand measurements is the least expensive option to record the geometry of a building. It can provide dimensions and relative positions of small and less complicated objects, but they can become less accurate and uneconomic for larger objects.

Total station theodolites (TSTs) can be used for the collection of data, as well as to survey a site control network, which is usually the first step to precisely identify the scanning points for other survey techniques (Historic England, 2018).

\subsection{Photogrammetry}

Photogrammetry is the determination of accurate measurements and three-dimensional data from photographs (Matthews, 2008). It is based on using images taken at different viewpoints to record the 3D geometry of a building or object (Dore and Murphy, 2017). Photogrammetry includes areal photogrammetry and close-range photogrammetry, which share the same main principles of triangulation where lines of sight (rays) from two different camera locations are joined to a common point on the object. the three-dimensional location of the point is determined by the intersection of these rays (Dore and Murphy, 2017).

Although photogrammetry can be a less expensive technique compared to laser scanning as it can be carried out using lowcost digital cameras, the entire process requires a lot of processing time. However, its main advantages over laser scanning is the addition of high-quality imagery and colour information to the resulting data.

\subsection{Laser Scanning}

Laser Scanning is seen as the most accurate and efficient tool in the field of as-built survey and documentation. Laser scanning is defined by Boehler and Marbs, (2002) as "any device that collects $3 D$ coordinates of a given region of an object's surface automatically, in a systematic pattern at a high rate and achieving the results in near real time". Later, Grussenmeyer, P., (2016) stressed on the non-contact and active nature of the process in their definition of laser scanning "an active, fast and automatic acquisition technique using laser light for measuring, without any contact and in a dense regular pattern, $3 D$ coordinates of points on surfaces".
Laser scanning includes a wide range of technologies, range of measurement, accuracy and operation techniques. In terms of technology laser scanners are based on one of three ranging principles: triangulation, pulse (time-of-flight; ToF) or phasecomparison (Historic England, 2018). All three types of laser scanners produce a 3D point cloud of the scanned geometry. However, the range and accuracy capabilities from each method vary (Dore and Murphy, 2017). Laser scanners can be hand held, mounted on backpacks, tripod based, vehicle mounted or airborne (usually referred to as Lidar derived from Light Detection and Ranging). They can vary in range from under a metre to several kilometres and vary in accuracy from a fraction of a millimetre to $300 \mathrm{~mm}$, depending on the site requirements (Table 1).

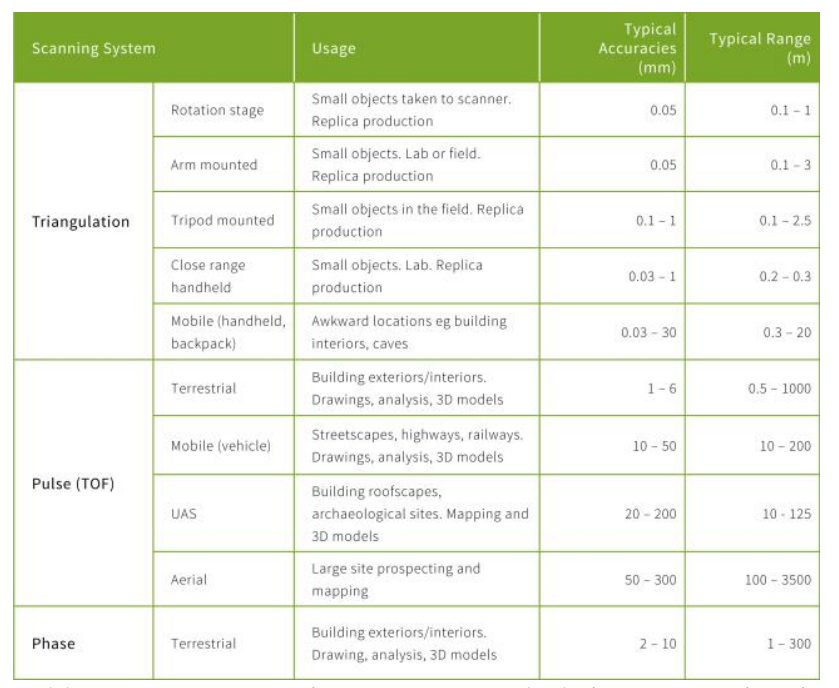

Table 1: Laser scanning systems and their uses. (Historic England, 2018)

The main disadvantage of laser scanning, beside the cost factor, is in the post-processing phase which can be very time and effort consuming to achieve the level of results required. Also, laser scanners are not as versatile or flexible as cameras regarding data capture. It can take over an hour at each position if higher resolutions and qualities are required. This contrasts with the instantaneous camera shot and the ability to use a camera in difficult locations (Historic England, 2018).

\subsection{Parametric Modelling \& Semantics}

Although more weight is on the 3D digital construction and visualisation of several datasets such as $3 \mathrm{D}$ laser scanning and photogrammetry, the most important part of the process of HBIM is to generate parametric model that needs to convert the surface of constructed facilities to the desired model. Then BIM system combines these parametric databases to facilitate collaborative design and facility management (Cheng, Yang and Yen, 2015).

One of the major challenges in modelling existing and historic buildings in HBIM is the lack of pre-defined parametric objects compared to the extensive libraries used to model new buildings. This requires the development of methodologies and algorithms to use data survey to model within BIM software (Murphy, McGovern and Pavia, 2013) (Chevrier et al., 2010). These models should contemplate about the level of detail and simplification of the models suitable for conservation projects. 
While offering the possibility to modify the parameters of the shape of the architectural elements, in particular, of historical objects that are often irregular, in an isotropic manner (Brumana et al., 2013).

Many attempts were done to build parametric objects libraries for historic buildings for various contexts (Wazeri, 2014) (Murphy, McGovern and Pavia, 2013) (Baik et al., 2014) (Chevrier et al., 2010). However, this area still needs more research to address different buildings elements and different historical eras, to create extensive parametric object libraries, as well as, automated object recognition tools, that can facilitate parametric modelling process.

A developing research area in the field of laser scanning is the process of converting point cloud into semantically rich BIM models (Carbonari, 2018). This can be done by creating algorithms that can learn the unique features of different types of surfaces and the contextual relationships between them and uses this knowledge to automatically label patches as walls, ceilings, or floors etc.. (Xiong et al., 2013). This technology, while still in its infancy, has great potentials for facilitating the automated transformation of raw point cloud data into useful semantic BIM models in one step, which can contribute towards time and effort saving. However, a lot of research is still needed in this area.

\section{PATHOLOGY}

Investigating and documenting the pathology of heritage buildings has a significant impact on the decisions and process of its conservation, renovation, retrofitting and management. Pathological investigations focus on studying the quality of the materials and structural system of the building, they also study original materials and construction methods, material degradation, historic fabric developments (Historic England, 2017) and structural decay that can result from design errors, erroneous interventions or neglect (Theodossopoulos and Sinha, 2008). Therefore, pathological investigation can be categorised into material pathology and structural pathology. It can be conducted using various tools, however, the geometry capturing tools remain the most used tools to investigate the buildings pathology, unless subsurface investigations are required.

\subsection{Materials Survey}

Material pathology aims to investigate material characterisation and properties, damage and temporal decay (Pocobelli, 2015). Outer skin material survey could be achieved using photogrammetry or laser scanning. However, they don't help in subsurface material survey, which needs different investigation tools, be it invasive or non-invasive, such as; Wet Chemistry which clarifies the pathology type; Optical Microscope to defines the pathology origin; Ultra-Violet (UV) Lighting and Infrared Imaging to detect organic matter; Fourier Transform Infrared (FTIR) Spectroscopy to identify materials (Pocobelli, 2015).

An innovative use of thermal scanning can help in surveying historic buildings and contributes to the HBIM modelling process. As a non-destructive technology it can be useful in investigating the building envelope and identifying structural system and near surface properties of material composition, decay, damages and moisture (Stober et al., 2018). These data enable detection of near surface areas of different material properties which in turn helps in planning of any material sampling needed or detailed inspection of structure and nonstructural parts of the building. Infrared thermography also contributes to indicate the energy leakage and enable planning the measures for increasing of its energy efficiency.

Stober et al., (2018) used infrared passive thermography to identify the invisible materials and structural system of the atrium facade of their case study of the Palace of the Slavonian General Command in Osijek in northern Croatia built in the 18th century and witnessed many changes till the early 20th century (Figure 3). Their investigations combined modelling of the existing 2D drawings of the current state of the building and Laser scanning of the baroque plastic entrance of the building that was integrated into the BIM model. Then they performed Thermal energy assessment of atrium wall surfaces to identify materials, construction system and thermal bridges of the 20th century reconstruction of the atrium (Figure 4). The last phase was interpretation of historical documentation over time in reverse engineering to model the building over different periods of time.

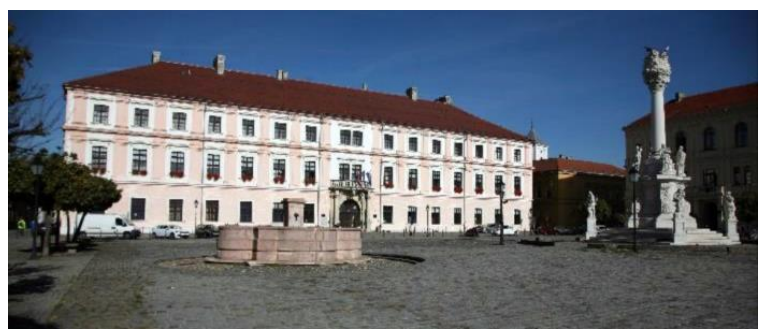

Figure 3: The Palace of the Slavonian General Command in Osijek in northern Croatia. (Stober et al., 2018)
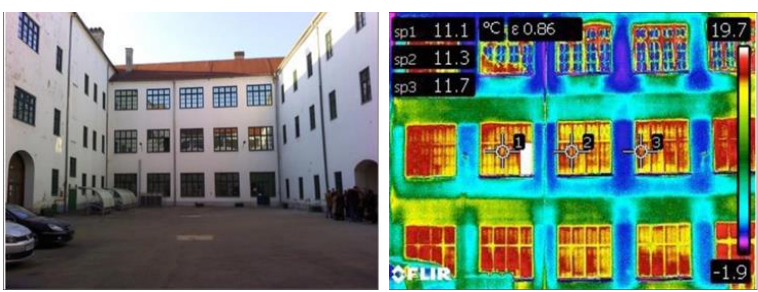

Figure 4: Using thermal imagery to identify the structure system, different materials and thermal bridges. (Stober et al., 2018)

\subsection{Structural Survey}

Structural pathology represents a great challenge and a main aspect to shape the conservation requirements of heritage buildings. Geometric survey could help to indicate structural pathology, but, in many cases more in depth structural investigations would be needed.

An example of structural survey can be seen in the work of Banfi et al., (2017) as they used HBIM for structural health monitoring for the documentation of the medieval bridge "Azzone Visconti" in Lecco in Italy. They combined 3D digital survey, parametric modelling and monitoring datasets for the development of a system for archiving and visualizing structural health monitoring data. The project consisted of a laser scanning survey to capture the irregular shape of the bridge (Figure 5). Then they used photogrammetry to generate accurate orthophotos of the elevations (Figure 6) as they provide a photorealistic visualisation, which were used in different stages of the project, for instance for planning the location of destructive and non-destructive analysis and a complete 
stratigraphic analysis. Then they performed a geometric levelling to monitor vertical movements of the bridge using a series of trucks and metallic coils to test the bearing capacity by alternately loading the different bridge spans to determine the deformation of the bridge under these loads (Figure 7) (Banfi et al., 2017).

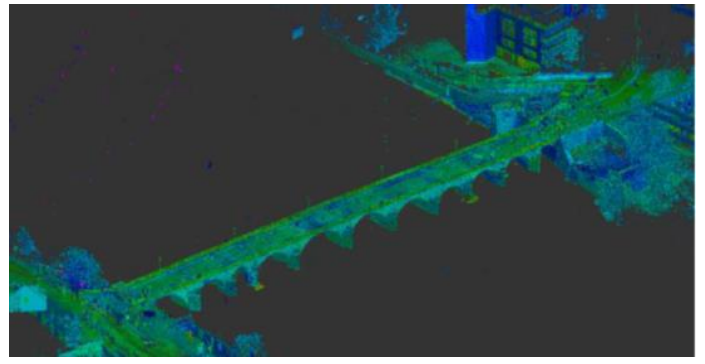

Figure 5: Laser scanning of Azzone Visconti bridge. (Banfi et al., 2017)
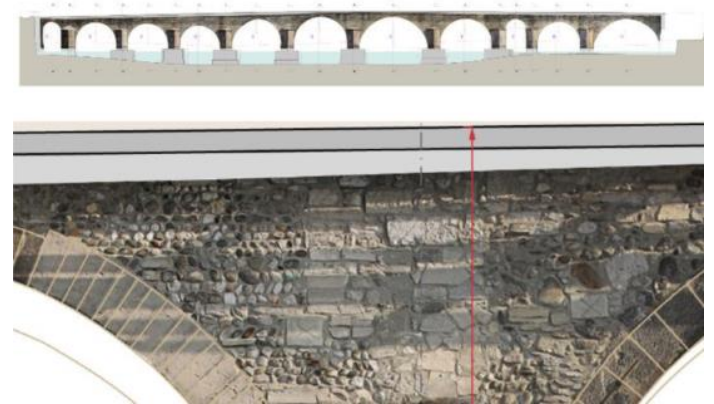

Figure 6: Orthophoto of the elevations of Azzone Visconti bridge. (Banfi et al., 2017)

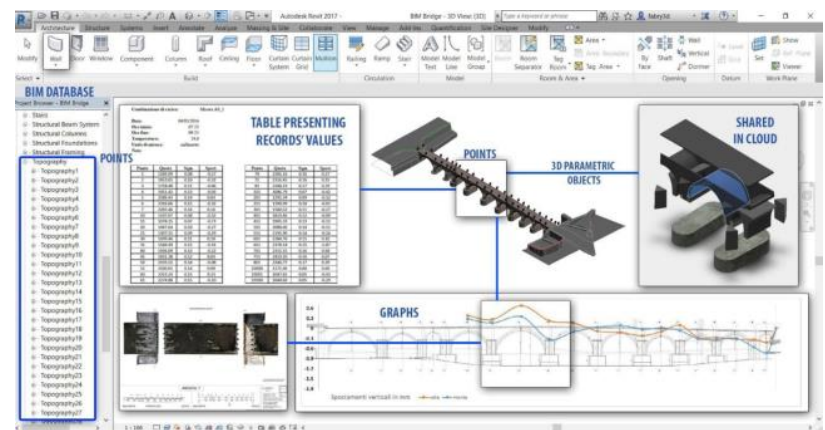

Figure 7: HBIM of the Azzone Visconti bridge including the model and the levelling results. (Banfi et al., 2017)

\section{PERFORMANCE}

Documentation and integration of the building performance is a major contribution of HBIM, that can contribute towards the decisions of design, retrofitting and management of the heritage building. Building performance in its broad understanding can represent many aspects such as energy performance, thermal performance, visual performance, acoustic performance, indoor air quality, systems efficiency, as well as functional and structural performance.

HBIM enables to iteratively test, analyse and improve a building design. This procedure is called Building Performance Analysis (BPA) (Brumana et al., 2013), as HBIM models contain both geometric information and semantic characteristics of the structure. Therefore it is possible to estimate life-cycle energy costs, annual consumption and potential energy savings by using design alternatives (Díaz-Vilariño et al., 2012). However, the most challenging aspect is to initially assess the building and its fabric performance and sustainability.

In the aforementioned case of St. Maria church in Scaria d'Intelvi, the researchers performed a building performance analysis through simulation, using a simplified version of the model. This simulation, however, was based on a lot of parameters taken as assumptions just to start the process (Figure 8) (Brumana et al., 2017).

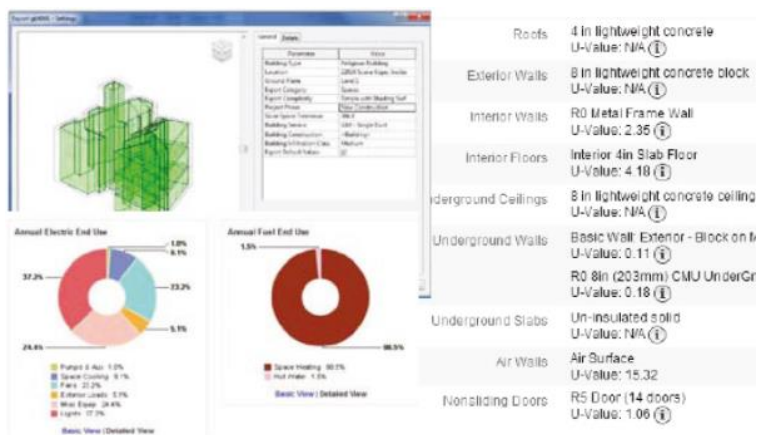

Figure 8: The model spaces and some parameters of the BPA of St. Maria church. (Brumana et al., 2017)

In another innovative case study conducted by Wang and Cho, (2015) they tried to combine laser scanning of an existing building with thermal imaging to help assess the thermal performance of the outer envelope of the building. For this purpose, they proposed a framework by developing a hybrid 3D LIDAR system with an IR camera to measure the temperature of the building`s surface so the temperature data are automatically fused with corresponding points during the data collection process and every point of the point cloud is defined by its $x-y-z$ coordinates and corresponding temperature data (Figure 9)(Figure 10). As-is BIM was automatically created by a building envelope recognition algorithm. After converting the file format into gbXML, the as-is BIM was imported into energy analysis software to conduct building performance analysis that can assist in retrofit decision making (Wang and Cho, 2015).

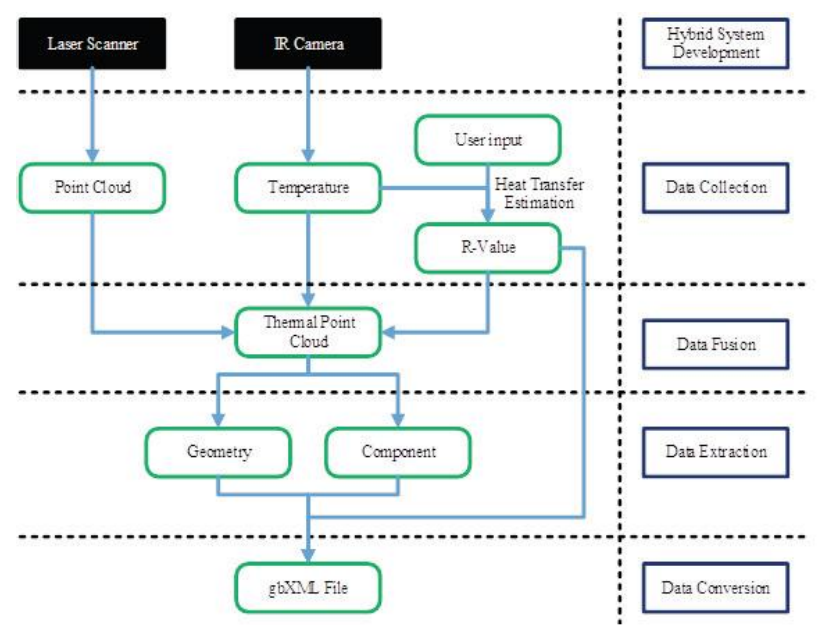

Figure 9: Framework for sustainability assessment proposed by (Wang and Cho, 2015)

In this case, unlike the previous one, the building performance analysis was based on actual thermal performance data collected from the fabric of the building itself, instead of starting with a 
model and assuming some parameters to perform the simulation.

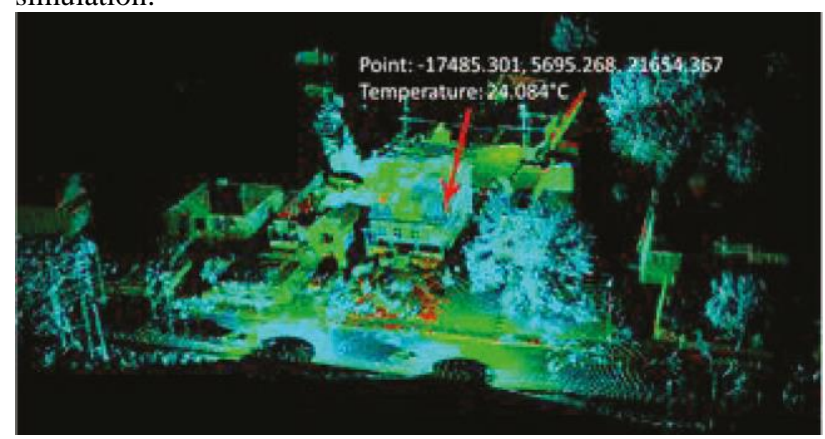

Figure 10: The point cloud of the building including the thermal information.

\section{CONCLUSION}

HBIM can represent a significant added value to the processes of documentation, conservation, design, construction and management of heritage buildings. It can also contribute towards the dissemination of the build heritage for the wider audience through virtual reality (VR) and augmented reality (AR) technologies. HBIM is of great value especially in the phase of survey, investigation and documentation of heritage buildings, as it represents a platform that can combine and integrate different sets of data from various sources. These data differ dramatically from tangible and accurately measured data, to intangible qualitative data, while all of them contribute towards better understanding and interpretation of the heritage building; its fabric, construction systems, performance and historical morphology. These data can be clearly categorised into four significant domains of data; the archaeological/historic domain, the geometrical survey, the pathological survey and the building performance analysis.

Many tools can be used to investigate different data domains, such as the $3 \mathrm{D}$ scanning and photogrammetry that, besides being the most convenient tools for capturing the building geometry, can contribute towards the analysis of its construction methods, materials, historical phases and even thermal behaviour when combined with thermal imaging camera. The same can be said concerning thermal imaging tools that can also help to identify sub-surface materials of the heritage building and to analyse its structural system.

3D survey, such as photogrammetry and laser scanning, are by far the most studied and rapidly developing tools in the heritage buildings data capturing process. However, converting these 3D scans of heritage building irregular and non-standardised elements into HBIM parametric objects represents a great challenge and an area where more research is needed in order to address different buildings elements and different historical eras, to create extensive parametric object libraries, as well as, automated object recognition tools, that can facilitate parametric modelling process. Semantic model recognition is also a developing area that have great potentials in the process of converting point clouds into useable semantic BIM models. This research area needs to be addressed in further research and development.

Although some innovative attempts have been done towards pathological investigations and building performance data integration into HBIM, more research is still needed, and more ideas could improve our approaches towards heritage building documentation and HBIM implementation in order to broaden our understanding of heritage buildings and the different aspects of their performance that can be of great help in planning their conservation, design, retrofitting and management.

\section{REFERENCES}

Albourae, A. T., Armenakis, C. and Kyan, M. (2017) 'Architectural heritage visualization using interactive technologies', International Archives of the Photogrammetry, Remote Sensing and Spatial Information Sciences - ISPRS Archives, 42(2W5), pp. 7-13. doi: 10.5194/isprs-archives-XLII2-W5-7-2017.

Azhar, S. et al. (2011) 'Building information modeling for sustainable design and LEED ${ }^{\circledR}$ rating analysis', Automation in Construction. Elsevier B.V., 20(2), pp. 217-224. doi: 10.1016/j.autcon.2010.09.019.

Azhar, S. and Brown, J. (2009) 'Bim for sustainability analyses', International Journal of Construction Education and Research, 5(4), pp. 276-292. doi: 10.1080/15578770903355657.

Baik, A. et al. (2014) 'Jeddah historical building information modeling "JHBIM"-object library', ISPRS Annals of the Photogrammetry, Remote Sensing and Spatial Information Sciences, 2(5), pp. 41-47. doi: 10.5194/isprsannals-II-5-412014.

Banfi, F. et al. (2017) 'Historic bim: A new repository for structural health monitoring', International Archives of the Photogrammetry, Remote Sensing and Spatial Information Sciences - ISPRS Archives, 42(5W1), pp. 269-274. doi: 10.5194/isprs-Archives-XLII-5-W1-269-2017.

Barazzetti, L. and Banfi, F. (2017) 'Mixed Reality and Gamification for Cultural Heritage', Mixed Reality and Gamification for Cultural Heritage, (November). doi: 10.1007/978-3-319-49607-8.

Boehler, W. and Marbs, A. (2002) '3D scanning instruments', Proceedings of the CIPA WG 6 International Workshop on Scanning for Cultural Heritage Recording, pp. 9-18. Available at: http://www.i3mainz.fhmainz.de/publicat/korfu/p05_Boehler.pdf.

Brumana, R. et al. (2013) 'From survey to HBIM for documentation, dissemination and management of built heritage: The case study of St. Maria in Scaria d'Intelvi', Proceedings of the DigitalHeritage 2013 - Federating the 19th Int'l VSMM, 10th Eurographics GCH, and 2nd UNESCO Memory of the World Conferences, Plus Special Sessions fromCAA, Arqueologica 2.0 et al., 1(May 2014), pp. 497-504. doi: 10.1109/DigitalHeritage.2013.6743789.

Brumana, R. et al. (2017) 'HBIM challenge among the paradigm of complexity, tools and preservation: The basilica $\mathrm{Di}$ collemaggio 8 years after the earthquake (L'aquila)', International Archives of the Photogrammetry, Remote Sensing and Spatial Information Sciences - ISPRS Archives, 42(2W5), pp. 97-104. doi: 10.5194/isprs-archives-XLII-2-W5-97-2017. 
Bryan, P. et al. (2009) Metric Survey Specifications for Cultural Heritage. Edited by D. Andreews. English Heritage. Available at: http://archaeologydataservice.ac.uk/archiveDS/archiveDownloa $\mathrm{d}$ ?t=arch-1416-1/dissemination/pdf/9781848021716.pdf.

Carbonari, G. (2018) 'SUSTAINABLE FACILITIES MANAGEMENT WITH THE SUPPORT OF BUILDING INFORMATION MODELLING', (February).

Cheng, H. M., Yang, W. Bin and Yen, Y. N. (2015) 'BIM applied in historical building documentation and refurbishing', International Archives of the Photogrammetry, Remote Sensing and Spatial Information Sciences - ISPRS Archives, 40(5W7), pp. 85-90. doi: 10.5194/isprsarchives-XL-5-W7-85-2015.

Chevrier, C. et al. (2010) 'Parametric Documenting of Built Heritage: 3D Virtual Reconstruction of Architectural Details', International Journal of Architectural Computing, 8(2), pp. 135-150. doi: 10.1260/1478-0771.8.2.135.

Díaz-Vilariño, L. et al. (2012) 'As-built BIM with shades modeling for energy analysis', Proceedings of the 2012 18th International Conference on Virtual Systems and Multimedia, VSMM 2012: Virtual Systems in the Information Society, pp. 353-359. doi: 10.1109/VSMM.2012.6365945.

Dore, C. and Murphy, M. (2017) 'CURRENT STATE OF THE ART HISTORIC BUILDING INFORMATION MODELLING', The International Archives of the Photogrammetry, Remote Sensing and Spatial Information Sciences, XLII-2/W5(5), pp. 185-192. doi: 10.5194/isprsarchives-XLII-2-W5-185-2017.

Fai, S. et al. (2011) 'Building Information Modelling and Heritage Documentation', Proceedings of the 23rd International Symposium, International Scientific Committee for Documentation of Cultural Heritage (CIPA), pp. 12-16.

Grussenmeyer, P., et al (2016) 'Basics of range- based modelling techniques in cultural heritage recording.', in $3 D$ Recording, Documentation and Management of Cultural Heritage.

Habibi, S. (2017) 'The promise of BIM for improving building performance', Energy and Buildings. Elsevier B.V., 153, pp. 525-548. doi: 10.1016/j.enbuild.2017.08.009.

Historic England (2017) BIM for Heritage Developing a Historic Building Information Model. Swindon. Available at: https://historicengland.org.uk/advice/technical-

advice/recording-heritage/.

Historic England (2018) '3D Laser Scanning for Heritage: Advice and Guidance on the Use of Laser Scanning in Archaeology and Architecture.'

Koller, D., Frischer, B. and Humphreys, G. (2009) 'Research challenges for digital archives of 3D cultural heritage models', Journal on Computing and Cultural Heritage, 2(3), pp. 1-17. doi: 10.1145/1658346.1658347.

Letellier, R. (2007) Recording, Documentation, and Information Management for the Conservation of Heritage
Places. guiding principles. Los Angeles: The Getty Conservation Institute. doi: 363.6’9 GET.

Logothetis, S., Delinasiou, A. and Stylianidis, E. (2015) 'Building Information Modelling for Cultural Heritage: A review', ISPRS Annals of Photogrammetry, Remote Sensing and Spatial Information Sciences, II-5/W3(September), pp. 177-183. doi: 10.5194/isprsannals-II-5-W3-177-2015.

Matthews, N. A. (2008) Aerial and Close-Range Photogrammetric Technology: Providing Resource Documentation, Interpretation, and Preservation., Technical Note 428. Denver, Colorado: U.S. Department of the Interior, Bureau of Land Management, National Operations Center, Denver, Colorado. Available at: https://permanent.access.gpo.gov/gpo67520/TN_428.pdf.

Murphy, M., McGovern, E. and Pavia, S. (2013) 'Historic Building Information Modelling - Adding intelligence to laser and image based surveys of European classical architecture', ISPRS Journal of Photogrammetry and Remote Sensing, 76, pp. 89-102. doi: 10.1016/j.isprsjprs.2012.11.006.

Osello, A., Lucibello, G. and Morgagni, F. (2018) 'HBIM and Virtual Tools: A New Chance to Preserve Architectural Heritage', Buildings, 8(1), p. $12 . \quad$ doi: 10.3390/buildings8010012.

Pocobelli, D. P. (2015) 'Can heritage be high-tech ? Building Information Modelling ( BIM ) for built heritage Material characterisation Terrestrial Data Aquisition Points Cloud Pathologies Revit 3D Model Future work', (2012), p. 2015.

Stober, D. et al. (2018) 'Application of HBIM as a Research Tool for Historical Building Assessment', 4(7), pp. 1565-1574.

Theodossopoulos, D. and Sinha, B. (2008) 'Structural safety and failure modes in Gothic vaulting systems', ... Int. Seminar on Structural ..., pp. 2-9. Available at: http://www.research.ed.ac.uk/portal/files/8768078/Structural_S afety_and_failure_modes_in_Gothic_vaulting_systems.pdf.

Volk, R., Stengel, J. and Schultmann, F. (2014) 'Building Information Modeling (BIM) for existing buildings - Literature review and future needs', Automation in Construction. Elsevier B.V., 38(October 2017), pp. 109-127. doi: 10.1016/j.autcon.2013.10.023.

Wang, C. and Cho, Y. K. (2015) 'Performance Evaluation of Automatically Generated BIM from Laser Scanner Data for Sustainability Analyses', Procedia Engineering. Elsevier B.V., 118, pp. 918-925. doi: 10.1016/j.proeng.2015.08.531.

Wazeri, Y. H. (2014) 'the Farthest Mosque or the Alleged Temple an Analytic Study', Journal of Islamic Architecture, 2(3), pp. 132-145. doi: 10.18860/jia.v2i3.2462.

Xiong, X. et al. (2013) 'Automatic Creation of Semantically Rich 3D Building Models from Laser Scanner Data', Automation in Construction, (31), pp. 325-337. 